\title{
Astragaloside IV prevents high glucose-induced cell apoptosis and inflammatory reactions through inhibition of the JNK pathway in human umbilical vein endothelial cells
}

\author{
LIANGZHEN YOU ${ }^{1,2}$, ZHAOHUI FANG ${ }^{2}$, GUOMING SHEN ${ }^{1}$, QIN WANG $^{1}$, YING HE ${ }^{1}$, SHE YE ${ }^{1}$, \\ LIU WANG $^{1}$, MENGJIE HU ${ }^{1}$, YIXUAN LIN ${ }^{1}$, MENGMENG LIU $^{1}$ and AIJUAN JIANG ${ }^{1}$ \\ ${ }^{1}$ Graduate Institute, Anhui University of Chinese Medicine; ${ }^{2}$ Department of Endocrinology, \\ The First Affiliated Hospital of Anhui University of Chinese Medicine, Hefei, Anhui 230031, P.R. China
}

Received June 25, 2018; Accepted November 30, 2018

DOI: $10.3892 / \mathrm{mmr} .2019 .9812$

\begin{abstract}
Endothelial dysfunction is a key pathophysiological step in early stage diabetes mellitus (DM) macrovascularcomplications and is also crucial in the inflammatory mechanisms of macrovascular complications. However, there is currently no effective intervention to improve endothelial dysfunction associated with DM macrovascular complications. Astragaloside IV (AS-IV), which can be extracted from the traditional Chinese medicine Astragalus membranaceus, has potential therapeutic effects on DM and its complications. The present study evaluated the effect of AS-IV on high glucose-induced human umbilical vein endothelial cell (HUVEC) injury and its possible mechanism. The result indicated that AS-IV has a significant protective effect on high glucose-induced HUVEC injury. AS-IV could significantly promote cell proliferation, reduce apoptosis and decrease the protein and mRNA expression levels of tumor necrosis factor- $\alpha$ and interleukin- $1 \beta$ in HUVECs. Furthermore, AS-IV could decrease the expression of phosphorylated c-Jun $\mathrm{NH}_{2}$-terminal kinase (JNK) phosphorylated apoptosis signal-regulating kinase 1 , cytochrome $\mathrm{c}$, cleaved-caspase- 9 , cleaved-caspase- 3 and the relative ratio of B-cell lymphoma-2 associated X protein/B-cell lymphoma-2 in HUVECs. In conclusion, the present study demonstrated that AS-IV could suppress apoptosis and inflammatory reactions promoted by high glucose conditions in HUVECs by inhibiting
\end{abstract}

Correspondence to: Professor Zhaohui Fang, Department of Endocrinology, The First Affiliated Hospital of Anhui University of Chinese Medicine, 103 Meishan Road, Hefei, Anhui 230031, P.R. China

E-mail: fangzhaohui111@163.com

Professor Guoming Shen, Graduate Institute, Anhui University of Chinese Medicine, 103 Meishan Road, Hefei, Anhui 230031, P.R. China

E-mail: shengm_66@163.com

Key words: astragaloside IV, high glucose, c-Jun $\mathrm{NH}_{2}$-terminal kinase pathway, cell apoptosis, inflammation the JNK signaling pathway. These findings suggest that AS-IV could inhibit the process of endothelial dysfunction in diabetic macrovascular complications.

\section{Introduction}

Macrovascular complications, mainly characterize the pathological change of atherosclerosis, are primarily associated with cardiovascular and cerebrovascular diseases. In addition, as the most common complications of DM, they are also the main causes of fatality and disability in DM patients (1). Endothelial dysfunction is a crucial pathophysiological step in the early stages of macrovascular complications and is an initial event of atherogenesis (2). Under normal conditions, apoptosis and the proliferation rate of vascular endothelial cells tends to be low in order to maintain the balance and the stability of blood vessels (3). Increased endothelial cell apoptosis is one of the predominant characteristics of endothelial dysfunction, which may promote smooth muscle cell proliferation and migration, increase blood coagulation, enhance leukocyte infiltration into the endothelium, and give rise to endothelial dysfunction and atherothrombosis (4). Research has indicated the role of inflammation in the pathogenesis of macrovascular complications of DM (5-7). Furthermore, glucotoxicity and inflammation can destroy endothelial function, leading to endothelial dysfunction and atherogenesis (8-10). Previous studies have demonstrated that high concentrations of glucose promote inflammatory damage in vascular endothelial cells in vitro (11-13). Therefore, inhibiting inflammation and decreasing cell apoptosis, which improve vascular endothelial dysfunction, are important to the treatment of macrovascular complications of DM.

C-Jun $\mathrm{NH}_{2}$-terminal kinase (JNK) is a type of serine/threonine protein kinase and a member of the family of mitogen-activated protein kinase (MAPK) (14). JNK is closely associated with cell differentiation, apoptosis, stress response and the occurrence and development of various human diseases (15). Inflammatory cytokines are the predominant activators of the JNK signaling pathway, which is a key regulator of pro-inflammatory gene expression $(16,17)$. It has previously been suggested that the activated JNK pathway 
contributes to vascular cell apoptosis and endothelial dysfunction under the stimulation of inflammatory cytokines (18-22). Furthermore, the JNK signaling pathway mediates apoptosis by modulating the activities of mitochondrial pro-apoptotic and anti-apoptotic proteins in the cytoplasm (23). Therefore, inhibition of JNK signaling pathway activation is an important target for improving vascular endothelial cell disorder in macrovascular complications of DM.

Radix Astragali, a famous Traditional Chinese Medicine, is the dry root of the perennial herbaceous plant, Astragalus menabranaceus (Fisch.) Bunge. Astragaloside IV (AS-IV) is one of the primary effective components of Astragali Radix that has potent protective effects on cardiovascular disease, DM and its complications (24). Furthermore, Astragali Radix has been reported to have a series of pharmacological actions, including anti-inflammatory and antioxidant effects, and can improve endothelial dysfunction and neovascularization associated with DM and its complications (25). Previous studies have revealed that AS-IV improves vascular endothelial dysfunction in diabetic rats through inhibiting the inflammatory pathways (26) and inhibiting inflammatory gene expression in lipopolysaccharide (LPS)-treated mice (27). However, few studies have investigated the protective effects and mechanisms of AST-IV with regard to glucotoxicity and inflammation in endothelial dysfunction in vitro. The present study aimed to determine whether AS-IV could prevent high glucose-induced cell apoptosis and inflammatory reactions through inhibition of the JNK signaling pathway in human umbilical vein endothelial cells (HUVECs). In addition, an accessible therapeutic strategy was suggested for the clinical treatment of diabetic macrovascular complications.

\section{Materials and methods}

Chemicals and drugs. AS-IV (Fig. 1) is a white crystalline powder and insoluble compound with $>98 \%$ purity. AS-IV has the molecular formula $\mathrm{C}_{41} \mathrm{H}_{68} \mathrm{O}_{14}$ and a molecular weight of 784.97 Da. AS-IV was purchased from the National Institute for Food and Drug Control (Beijing, China). The compound was dissolved in dimethyl sulfoxide (DMSO) to a concentration of $250 \mu \mathrm{M}$ in a stock solution. The stock solution was diluted with Dulbecco's modified Eagle's medium (DMEM). The final DMSO concentration did not exceed $0.5 \%(\mathrm{v} / \mathrm{v})$.

Anti-phosphorylated (phospho/p)-JNK, anti-JNK, anticleaved-caspase-3, anti-cleaved-caspase- 9 and anti- $\beta$-actin were obtained from Abcam (Cambridge, UK). Phosphoapoptosis signal-regulating kinase-1 (ASK1), ASK1, cytochrome c (Cyt-c) antibody, B-cell lymphoma-2-associated $\mathrm{X}$ protein (Bax) and B-cell lymphoma-2 (Bcl-2) antibodies were purchased from Cell Signaling Technology, Inc. (Danvers, MA, USA). SP600125, penicillin/streptomycin solution, $0.05 \%$ trypsin-EDTA, DMSO and MTT were purchased from Sigma-Aldrich; Merck KGaA (Darmstadt, Germany). DMEM and fetal bovine serum were purchased from HyClone (Logan, UT, USA). Radioimmunoprecipitation assay lysis and extraction buffer, horseradish peroxidase-conjugated AffiniPure goat anti-mouse immunoglobulin ( $\mathrm{Ig}) \mathrm{G}$ and anti-rabbit IgG antibodies and D-glucose were purchased from OriGene Technologies, Inc., (Beijing, China). Annexin V-fluorescein isothiocyanate (FITC) and propidium iodide (PI) were obtained

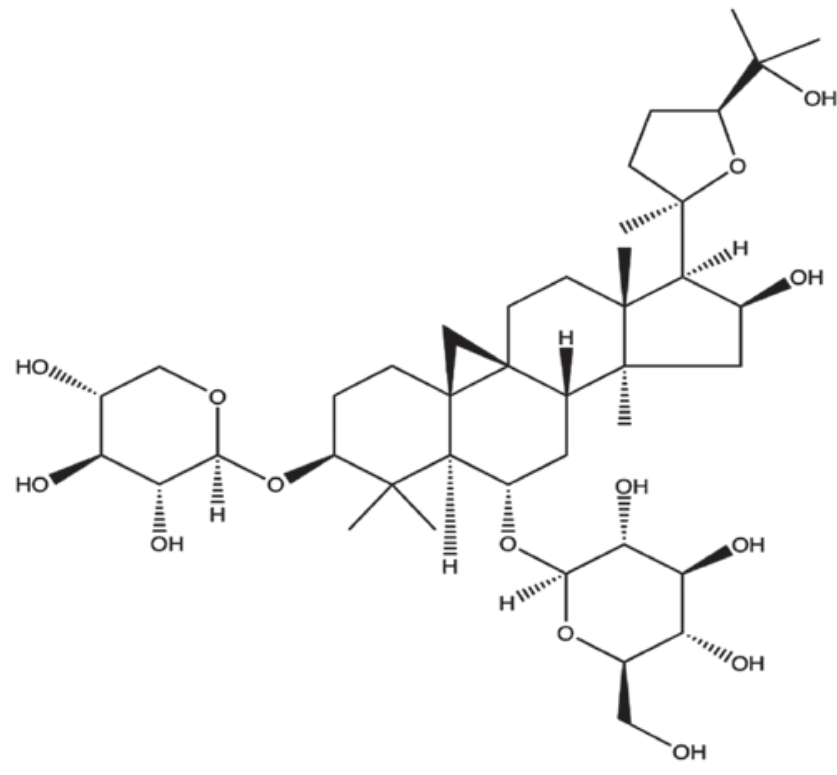

Figure 1. Chemical structure of astragaloside IV.

from Absin Bioscience, Inc. (Shanghai, China; http://www. absin.cn/). A Hoechst 33258 kit was purchased from Beijing Solarbio Science \& Technology Co., Ltd. (Beijing, China). ELISA kits for IL-1 $\beta$ (catalog no. SBJH0292) and TNF- $\alpha$ (catalog no. SBJH0038) were purchased from the Nanjing SenBeiJia Biological Technology Co., Ltd. (Nanjing, China). Polymerase chain reaction (PCR) primers were obtained from Sangon Biotech Co., Ltd. (Shanghai, China).

Cell culture and treatment. HUVECs were obtained from the Fudan Institutes of Biomedical Sciences Cell Resource Center (The Institutes of Biomedical Sciences, Fudan University, Shanghai, China) and cultured in DMEM supplemented with $10 \%$ fetal bovine serum, $100 \mu \mathrm{g} / \mathrm{ml}$ streptomycin and $100 \mathrm{U} / \mathrm{ml}$ penicillin in a humidified atmosphere containing $5 \% \mathrm{CO}_{2}$ at $37^{\circ} \mathrm{C}$. Experiments were performed with cells at $80 \%$ confluence.

The first series of experiments were designed to confirm the optimal glucose concentration to induce the cellular damage model and the optimal AS-IV concentration to protect against damaged cell. Doses of 5.55, 11.1,22.2,33.3 and 44.4 mM glucose were added to HUVECs $\left(2 \times 10^{5}\right.$ cells $\left./ \mathrm{ml}\right)$, which were cultured for 24, 48 and $72 \mathrm{~h}$. Doses of 0, 6.25, 12.5, 25, 50, 100, 200, 400, 800 and 1,600 $\mu \mathrm{M}$ AS-IV were added to HUVECs, which were cultured for $48 \mathrm{~h}$ in the solution of $5.55 \mathrm{mM}$ glucose. In addition, doses of 25, 50, $100 \mu \mathrm{M}$ AS-IV were added to HUVECs, which were cultured for $48 \mathrm{~h}$ in a solution of $33.3 \mathrm{mM}$ glucose.

The second series of experiments were designed to examine the protective effect and possible mechanism of AS-IV. Cells were divided into five groups at a density of $2 \times 10^{5}$ cells $/ \mathrm{ml}$ : i) The control group, where cells were cultured with $5.55 \mathrm{mM}$ glucose and treated with $30 \mathrm{mM}$ mannitol to balance the osmotic pressure in culture medium for $48 \mathrm{~h}$; ii) model group, where cell damage was induced by incubation with $33.3 \mathrm{mM}$ glucose for $48 \mathrm{~h}$; iii) the SP600125 inhibitor group, where cells were cultured with $33.3 \mathrm{mM}$ glucose for $48 \mathrm{~h}$ prior to the addition of $20 \mu \mathrm{M}$ SP600125 (JNK inhibitor); iv) AS-IV group, where cells were cultured in $33.3 \mathrm{mM}$ glucose for $48 \mathrm{~h}$ prior to the addition of $50 \mu \mathrm{M}$ AS-IV; and v) the AS-IV+SP600125 group, where cells 
were cultured in $33.3 \mathrm{mM}$ glucose for $48 \mathrm{~h}$ prior to the addition of $50 \mu \mathrm{M}$ AS-IV and $20 \mu \mathrm{M}$ SP600125. SP600125 was dissolved in DMSO (the final concentration did not exceed $0.5 \%$ ).

Cell viability assay. HUVECs in the logarithmic growth phase were seeded in 96-well culture plates at $2 \times 10^{5}$ cells/well. Following respective group treatments, $20 \mu \mathrm{l} \mathrm{MTT}(5 \mathrm{mg} / \mathrm{ml})$ was added to $100 \mu \mathrm{l}$ of culture medium in each well. A total of $4 \mathrm{~h}$ following this, the medium was removed and $150 \mu \mathrm{l}$ DMSO was added into each well. The absorbance was measured at $490 \mathrm{~nm}$ using an automated microplate reader (BioTek Instruments, Inc., Winooski, VT, USA). A total of five independent experiments were repeated in each group. Cell viability was calculated according to the following formula: Cell viability $(\%)=$ average absorbance of the treated group/average absorbance of the control group x $100 \%$.

Cell apoptosis assay. Apoptosis was assessed with the Hoechst 33258 staining method, followed by photofluorography. Following the respective group treatments, the nutrient solution was removed and cells were washed twice with PBS. Subsequently, the cells were fixed with $40 \mathrm{~g} / 1$ paraformaldehyde fluid at $4^{\circ} \mathrm{C}$ for $10 \mathrm{~min}$. Slides were then washed twice with PBS. Once PBS was removed, the nuclear DNA was stained with $5 \mathrm{mg} / \mathrm{ml}$ Hoechst 33258 at room temperature for $10 \mathrm{~min}$ and then visualized under a fluorescence microscope (BX50-FLA; Olympus Corporation, Tokyo, Japan). The viable HUVECs exhibited a uniform blue fluorescence throughout the nucleus, whereas the apoptotic cells had fragmented and condensed nuclei. The experiment was carried out three times.

Apoptosis rate was analyzed by labeling cells with Annexin V-FITC apoptosis assay kit (cat.no. abs50001; Absin Bioscience, Inc., Shanghai, China; www.absin.cn/). Following the treatment, cells were collected using EDTA-free trypsin to digest the cells, followed by centrifugation at $211 \mathrm{x} \mathrm{g}$ for $10 \mathrm{~min}$ at $4^{\circ} \mathrm{C}$ to collect the cells. Cells were suspended with $500 \mu \mathrm{l}$ binding buffer at a concentration of $1 \times 10^{6}$ cells $/ \mathrm{ml}$ and subsequently stained with $5 \mu \mathrm{l}$ annexin V-FITC at $4^{\circ} \mathrm{C}$ in the dark for $15 \mathrm{~min}$ followed by $10 \mu \mathrm{PI}$ at $4^{\circ} \mathrm{C}$ in the dark for $5 \mathrm{~min}$. Following this, cells were immediately examined using a flow cytometer (Beckman Coulter, Inc., Brea, CA, USA) with FlowJo software (version 7.6.1; Tree Star, Inc., Ashland, OR, USA).

ELISA analysis. The levels of IL-1 $\beta$ and TNF- $\alpha$ in culture supernatant were determined using commercial ELISA kits according to the manufacturers' protocols and determined using a microplate reader at 450-nm wavelength (Multiskan FC; Thermo Fisher Scientific, Inc., Waltham, MA, USA).

Reverse transcription-quantitative polymerase chain reaction $(R T-q P C R)$. Total RNA was isolated from HUVECs using TRIzol reagent (Invitrogen; Thermo Fisher Scientific, Inc.) according to the manufacturer's protocol. Template cDNA was prepared using a RevertAid First Strand cDNA Synthesis kit (Thermo Fisher Scientific, Inc.). Total RNA (5 $\mu \mathrm{g})$ was reverse transcribed to cDNA with 5X Reaction Buffer $(4 \mu \mathrm{l})$, Oligo(dT)18 (1 $\mu \mathrm{l})$, RevertAid Reverse Transcriptase (1 $\mu \mathrm{l})$, RiboLock RNase Inhibitor (1 $\mu \mathrm{l})$, dNTP Mix $(2 \mu \mathrm{l})$ and $\mathrm{ddH}_{2} \mathrm{O}$ to supplement to a total volume of $20 \mu \mathrm{l}$. The synthesis temperature protocol was $60 \mathrm{~min}$ at $42^{\circ} \mathrm{C}, 5 \mathrm{~min}$ at $70^{\circ} \mathrm{C}$ and $1 \mathrm{~min}$ at $4^{\circ} \mathrm{C}$. The qPCR using the Quanti Nova SYBR Green PCR kit (Qiagen $\mathrm{GmbH}$, Hilden, Germany). qPCR was performed using an ABI Prism 7500 Sequence Detection System (Applied Biosystems; Thermo Fisher Scientific, Inc.). The sequences of the primers were as follows: 5'-TCAGCCAATCTTCATTGC TC-3' (forward) and 5'-GCCATCAGCTTCAAAGAACA-3' (reverse) for interleukin (IL)-1 $\beta$; 5'-TTTGATCCCTGACAT CTGGA-3' (forward) and 5'-GGCCTAAGGTCCACTTGT GT-3' (reverse) for tumor necrosis factor (TNF)- $\alpha$; and 5'-GGG AAATCGTGCGTGACATTAAGG-3' (forward) and 5'-CAG GAAGGAAGGCTGGAAGAGTG-3' (reverse) for $\beta$-actin. The reaction conditions included $95^{\circ} \mathrm{C}$ for $10 \mathrm{~min}$, followed by 40 cycles of $95^{\circ} \mathrm{C}$ for $30 \mathrm{sec}, 58^{\circ} \mathrm{C}$ for $1 \mathrm{~min}$ and $72^{\circ} \mathrm{C}$ for $30 \mathrm{sec}$. Reaction specificity was confirmed by melting curve analysis. Gene expression profiles were normalized to $\beta$-actin and calculated using the $2^{-\Delta \Delta \mathrm{Cq}}$ method (28) for each sample.

Western blot analysis. Total proteins were extracted with a radioimmunoprecipitation assay buffer (OriGene Technologies, Beijing, China). Proteins from each experimental group were quantified using the bicinchoninic acid assay (BestBio, Shanghai, China). An equal amount of protein $(30 \mu \mathrm{g})$ was loaded and subjected to $10 \%$ SDS-PAGE. Gels were run at $120 \mathrm{~V}$ for $1.5 \mathrm{~h}$ and transferred to polyvinylidene fluoride membranes at $120 \mathrm{~V}$ for $2 \mathrm{~h}$. Non-specific protein binding was blocked with 5\% non-fat dried milk in Tris-buffered saline with Tween 20 (TBST; $10 \mathrm{mM}$ Tris-HCl, pH 7.4, $50 \mathrm{mM} \mathrm{NaCl}, 0.05 \%$ Tween-20) for $2 \mathrm{~h}$ at room temperature. Membranes were incubated with anti-phospho-JNK (1:1,000; rabbit monoclonal antibody, cat. no. ab124956), anti-JNK (1:1,000; cat. no. ab179461), anti-cleaved-caspase-3 (1:1,000; cat. no. ab49822), anti-cleaved-caspase-9 (1:1,000; cat. no. ab2324), anti-phospho-ASK1 (1:1,000; cat. no. 3764), anti-ASK1 (1:1,000; cat. no. 3762), anti-Cyt-c (1:1,000; cat. no. 11940), anti-Bax (1:1,000; cat. no. 2772), anti-Bcl-2 (1:1,000; cat. no. 3498) and anti- $\beta$-actin $\left(1: 1,000\right.$; cat. no. ab179467) overnight at $4^{\circ} \mathrm{C}$. After washing with TBST, the membranes were incubated with horseradish peroxidase (HRP)conjugated goat anti-rabbit IgG secondary antibody (1:20,000; cat. no. TA130015, OriGene Technologies) at room temperature for $2 \mathrm{~h}$. The signal was detected using an enhanced chemiluminescence substrate kit (GE Healthcare, Chicago, IL, USA). According to the manufacturer's protocol, immunoreactive bands of proteins were scanned with a digital gel imaging and analysis system (ProteinSimple, San Jose, CA, USA).

Statistical analysis. Datawere expressed as the mean \pm standard deviation of three independent experiments and analyzed using SPSS version 13.0 (SPSS Inc., Chicago, IL, USA). The Student's ttest was used for comparison between two groups. Multiple comparisons were achieved using one-way analysis of variance with the StudentNewmanKeuls test. $\mathrm{P}<0.05$ was considered to indicate a statistically significant difference.

\section{Results}

Effect of glucose on HUVEC viability. To confirm the optimal glucose concentration to induce the cellular damage model, the MTT assay was performed to observe HUVEC viability alterations in cells treated with glucose for 24,48 and $72 \mathrm{~h}$ 
A

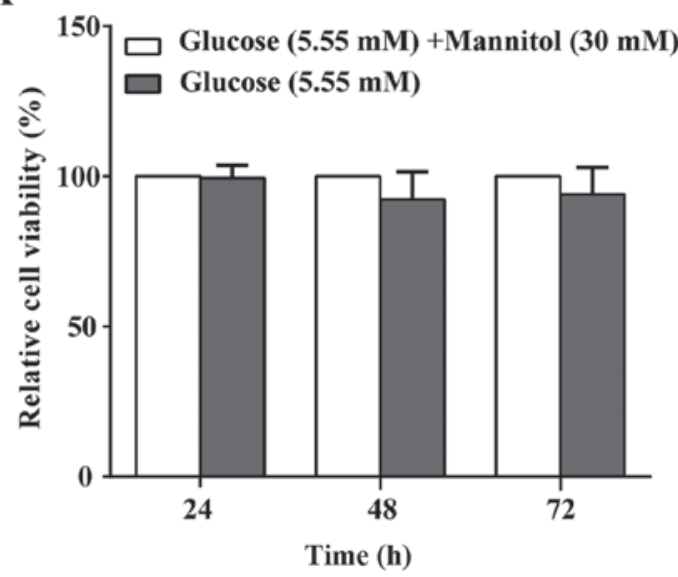

B

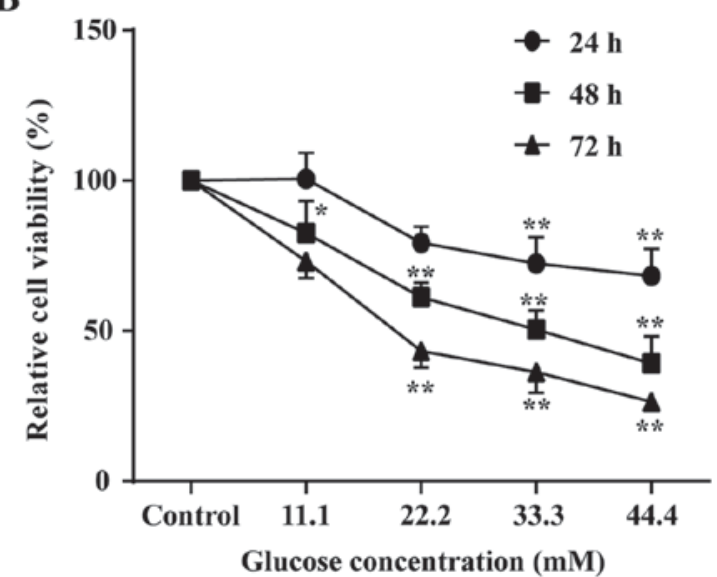

Figure 2. Effect of glucose on HUVEC viability. (A) Effects of mannitol on the viability of HUVECs at 24,48 and $72 \mathrm{~h}$. (B) Effects of glucose on the viability of HUVECs at 24, 48 and $72 \mathrm{~h}$ using different concentrations of glucose. Data of three experiments were presented as the mean \pm standard deviation. ${ }^{*} \mathrm{P}<0.05$ and ${ }^{* *} \mathrm{P}<0.01$ vs. the Control group (5.55 mM glucose concentration). HUVECs, human umbilical vein endothelial cells; AS-IV, astragaloside IV.

A

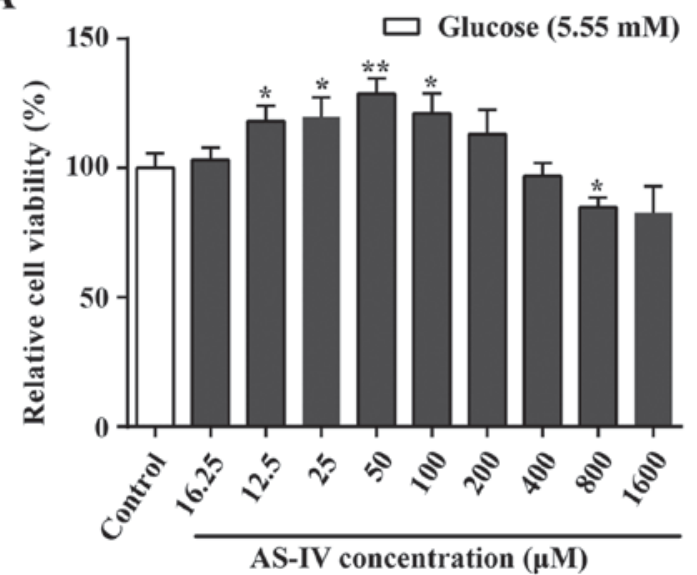

B

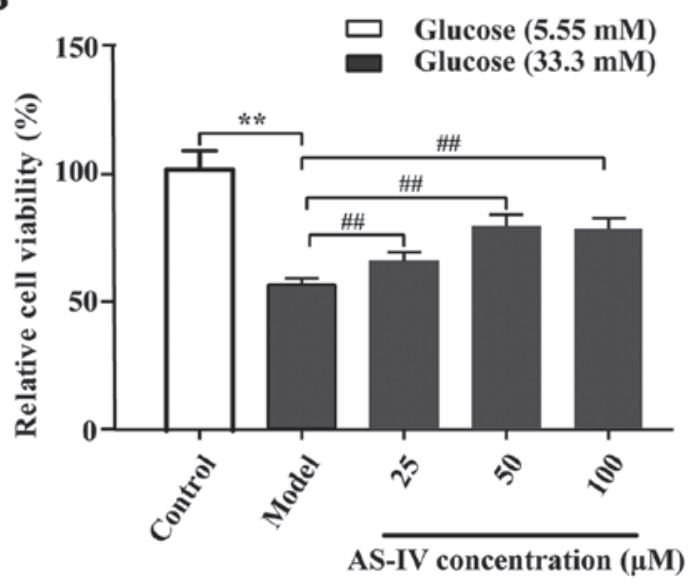

Figure 3. Effect of AS-IV on HUVEC viability. (A) Effects of AS-IV on the viability of HUVECs in $5.55 \mathrm{mM}$ glucose at 48 h. (B) Effects of AS-IV on the viability of HUVECs in $33.3 \mathrm{mM}$ glucose at $48 \mathrm{~h}$. Data of three experiments were presented as the mean \pm standard deviation. ${ }^{*} \mathrm{P}<0.05$ and ${ }^{* * *} \mathrm{P}<0.01 \mathrm{vs}$. the Control group (5.55 mM glucose concentration); ${ }^{\# \#} \mathrm{P}<0.01$ vs. the Model group (33.3 mM glucose concentration). HUVECs, human umbilical vein endothelial cells; AS-IV, astragaloside IV.

at different concentrations $(5.55-44.4 \mathrm{mM})$. As indicated in Fig. 2, glucose exhibited a time- and concentration-dependent inhibitory effect on cell viability. The $50 \%$ inhibitory concentration $\left(\mathrm{IC}_{50}\right)$ value for the HUVECs was $66.90 \mathrm{mM}$ at $24 \mathrm{~h}$ of glucose treatment; however, the maximal glucose treatment still failed to reach half of cell inhibition. The $\mathrm{IC}_{50}$ value was $21.89 \mathrm{mM}$ at $72 \mathrm{~h}$ of glucose treatment; however, the cells were unstable. Notably, the $\mathrm{IC}_{50}$ value was $32.46 \mathrm{mM}$ glucose treatment for $48 \mathrm{~h}$ and the cells were stable. Combining the results of previous studies $(29,30)$ with the present study results, the cell state was the most stable with $33.3 \mathrm{mM}$ glucose treatment for $48 \mathrm{~h}$. Therefore, $33.3 \mathrm{mM}$ glucose for $48 \mathrm{~h}$ was selected to induce the cellular damage model. In addition, there was no significant difference in HUVEC viability between cells treated with glucose mixed with mannitol and cells that received glucose alone (Fig. 2).

Effect of AS-IV on HUVEC viability. The AS-IV cell toxicity assay was performed (Fig. 3A). Data indicated that AS-IV could enhance cell viability over a specific concentration range $(16-200 \mu \mathrm{M})$. At higher concentrations $(800 \mu \mathrm{M})$, AS-IV significantly inhibited the cell viability compared with the control group $(\mathrm{P}<0.05)$. The effects of AS-IV on HUVEC viability under high glucose conditions were indicated (Fig. 3B). Data revealed that the cell viability was optimal when the concentration of AS-IV was $50 \mu \mathrm{M}$ $(\mathrm{P}<0.01)$. Therefore, the $50 \mu \mathrm{M}$ AS-IV was used in the later experiments.

Effect of AS-IV on cell apoptosis in HUVECs stimulated with high glucose conditions. Hoechst 33258 staining was performed to identify the nuclear morphology associated with apoptotic cell death. Exposure to high glucose conditions for $48 \mathrm{~h}$ increased the number of apoptotic cells (Fig. 4) and nuclei pyknosis was observed. Furthermore, a large number of chromosomal contractions could be observed in the model group. Furthermore, specific apoptotic cell nuclei were light blue and an apoptotic body was occasionally visible when compared 
A
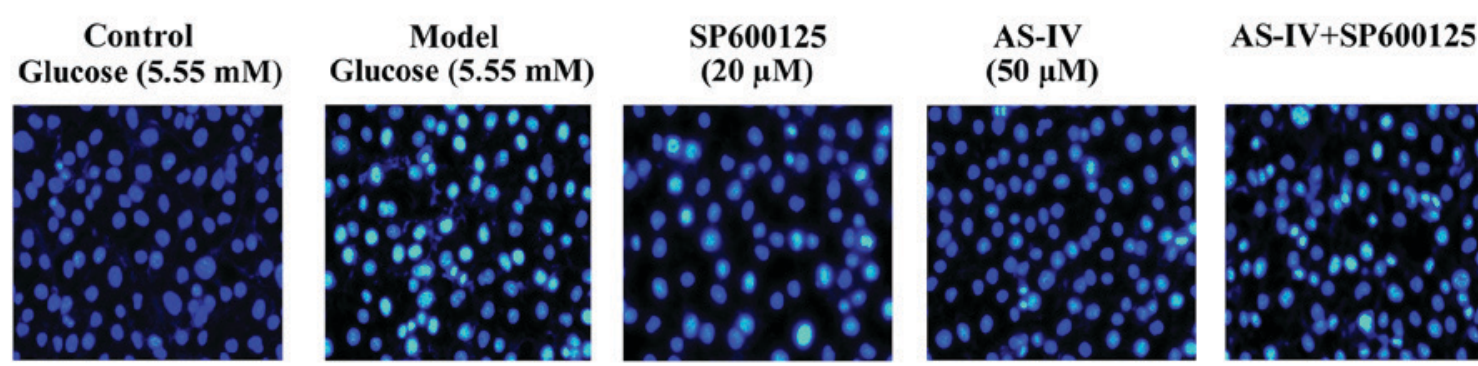

B

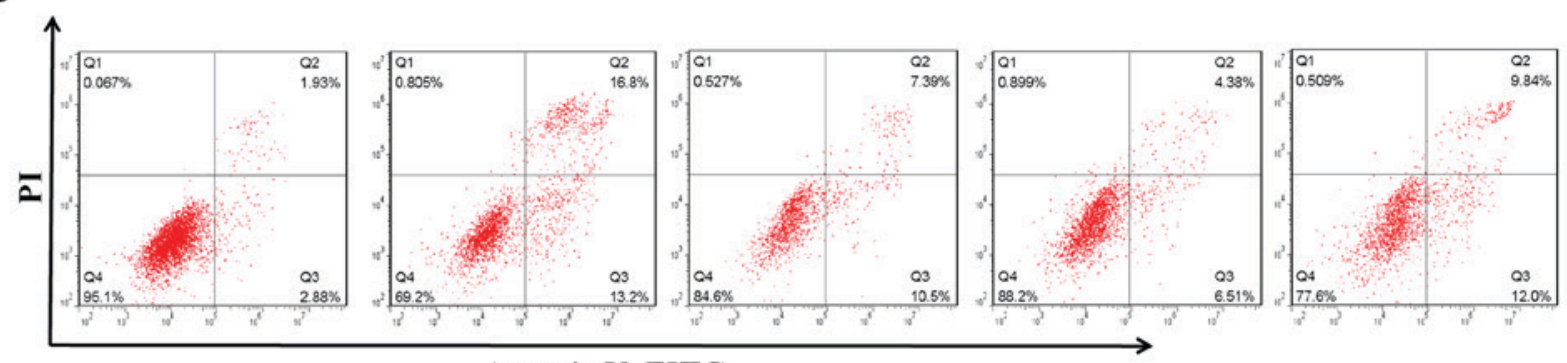

Annexin V-FITC

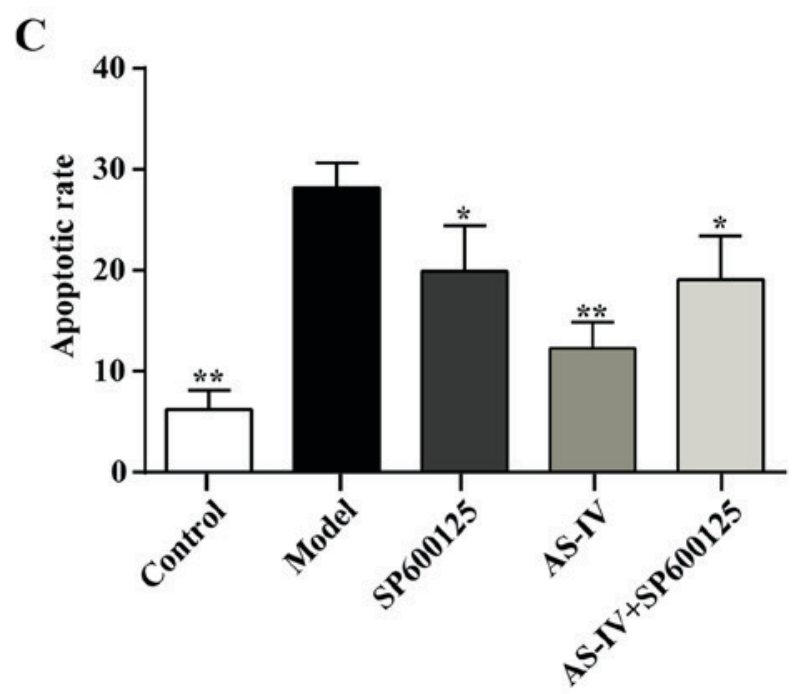

Figure 4. Effect of AS-IV on apoptosis in human umbilical vein endothelial cells stimulated with high glucose conditions. (A) Apoptotic status was determined using a fluorescent microscope (magnification, x200). (B) Apoptotic rates were assessed using annexin V-FITC and PI staining analysis. (C) Bar graph of apoptotic rates. Data of three experiments were presented as the mean \pm standard deviation. ${ }^{*} \mathrm{P}<0.05$ and ${ }^{* *} \mathrm{P}<0.01$ vs. the Model group. AS-IV, astragaloside IV; FITC, fluorescein isothiocyanate; PI, propidium iodide.

with the control group. The increased number of apoptotic cells was reversed with AS-IV treatment (Fig. 4). Similarly, the apoptosis rate of HUVECs was significantly decreased with AS-IV pre-treatment according to annexin V-FITC and PI staining analysis ( $\mathrm{P}<0.05$; Fig. $4 \mathrm{~B}$ and $\mathrm{C})$.

Effect of AS-IV on high glucose-stimulated inflammatory mediators. The cytokine levels of IL-1 $\beta$ and TNF- $\alpha$ in HUVECs were measured using an ELISA assay. As indicated in Fig. 5A, treatment of HUVECs with high glucose resulted in the significantly increased IL- $1 \beta$ and TNF- $\alpha$ levels compared with the control $(\mathrm{P}<0.01)$. However, IL-1 $\beta$ and TNF- $\alpha$ levels were significantly reduced following pre-treatment with AS-IV $(\mathrm{P}<0.01)$.
Effect of AS-IV on the mRNA expression levels of IL-1 $\beta$ and $T N F-\alpha$. To further investigate the expression of inflammatory factors, mRNA expression levels of IL- $1 \beta$ and TNF- $\alpha$ were measured by RT-qPCR. As indicated in Fig. 5B, stimulation with high glucose increased IL- $1 \beta$ and TNF- $\alpha$ mRNA expression levels in HUVECs. However, pretreatment with AS-IV with could significantly decrease the mRNA expression levels of IL-1 $\beta$ and TNF- $\alpha$ in HUVECs $(\mathrm{P}<0.01)$.

Effect of AS-IV on the expression of the JNK signaling pathway. The JNK signaling pathway helps regulate the inflammatory response. Western blot analysis was used to detect the protein expression levels of JNK, p-JNK, ASK1 and p-ASK1 in HUVECs in order to investigate the mechanism of action of 


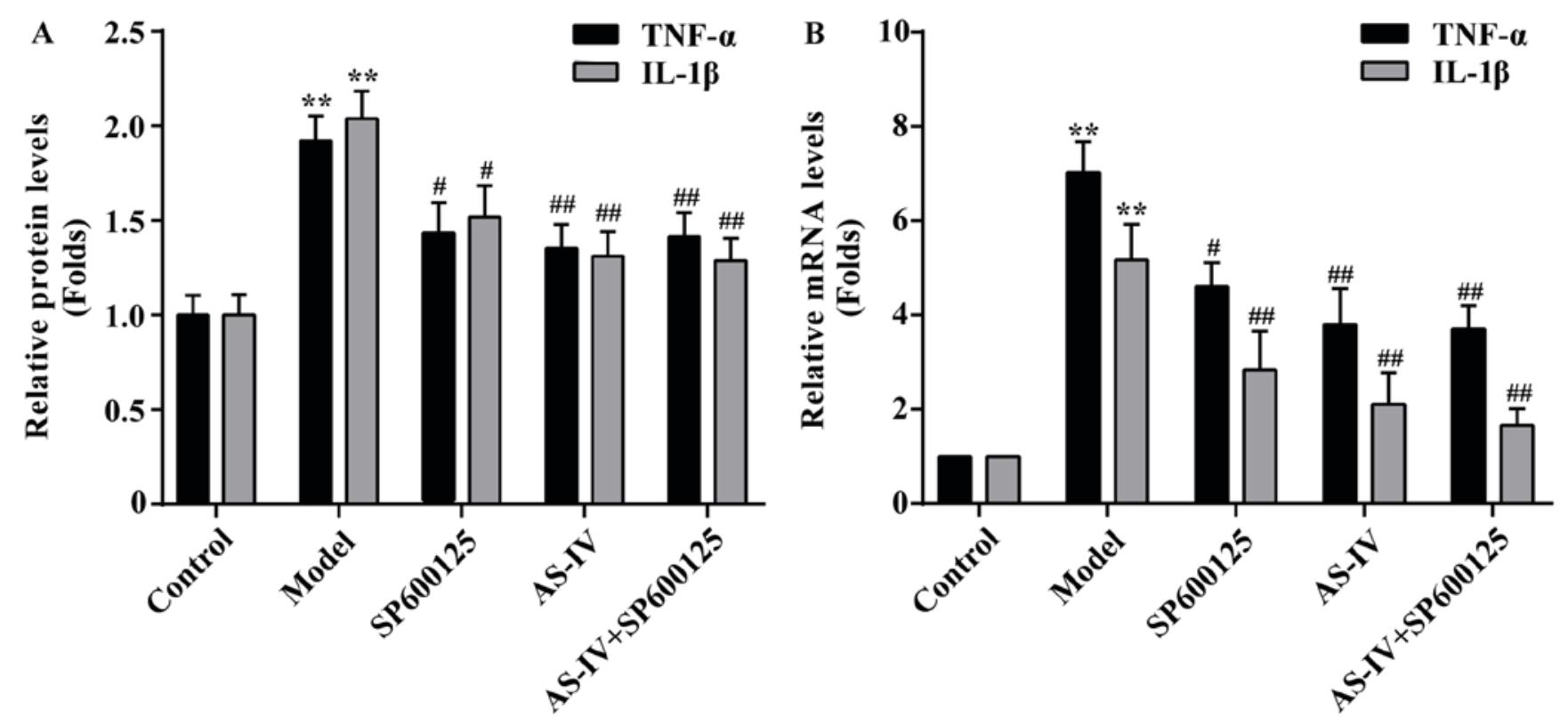

Figure 5. Effect of AS-IV on the inflammatory response of human umbilical vein endothelial cells stimulated with high glucose conditions. (A) Expression levels of IL- $1 \beta$ and TNF- $\alpha$ protein. (B) Expression levels of IL- $1 \beta$ and TNF- $\alpha$ mRNA. $\beta$-actin was used as an internal reference. Data of three experiments were presented as the mean \pm standard deviation. ${ }^{* * *} \mathrm{P}<0.01$ vs. the Control group; ${ }^{*} \mathrm{P}<0.05$ and ${ }^{\# \#} \mathrm{P}<0.01$ vs. the Model group. AS-IV, astragaloside IV; TNF, tumor necrosis factor; IL, interleukin.

AS-IV. As indicated in Fig. 6, stimulation with high glucose increased JNK and ASK1 phosphorylation in HUVECs. AS-IV and the combination of AS-IV and JNK inhibitor could decrease JNK and ASK1 phosphorylation $(\mathrm{P}<0.01$ or $\mathrm{P}<0.05)$. Notably, the JNK inhibitor could significantly decrease JNK phosphorylation $(\mathrm{P}<0.01)$; however, the JNK inhibitor was unable to significantly decrease ASK1 phosphorylation.

Effect of AS-IV on the expression levels of Bax and Bcl-2. In order to determine the effect of AS-IV on the protein expression levels of components associated with apoptosis and the JNK signaling pathway in HUVECs, the Bax and Bcl-2 protein expression levels were assessed. As indicated in Fig. 7, stimulation with high glucose increased the protein expression levels of Bax and decreased the expression levels Bcl-2 protein in HUVECs. AS-IV, the JNK inhibitor and the combination of AS-IV and JNK inhibitor could decrease the protein expression levels of Bax, increased the protein expression levels of Bcl-2 and significantly decreased the ratio of $\mathrm{Bax} / \mathrm{Bcl}-2$ (P<0.01; Fig. 7).

Effects of AS-IV on the expression levels of Cyt-c, cleaved-caspase-9 and cleaved-caspase-3. Apoptosis regulatory proteins $\mathrm{Bax}$ and $\mathrm{Bcl}-2$ are associated with the cell mitochondrial apoptotic pathways. Therefore, western blot analysis was performed to detect the expression of a series of key proteins involved in the mitochondrial apoptosis pathway, including Cyt-c, cleaved-caspase-9 and cleaved-caspase-3. As indicated in Fig. 7, stimulation with high glucose increased the protein expression levels of Cyt-c, cleaved-caspase-9 and cleaved-caspase-3; however, AS-IV, JNK inhibitor and the combination of AS-IV with JNK inhibitor could significantly decrease the expression levels of these proteins $(\mathrm{P}<0.05)$.

\section{Discussion}

The glucotoxicity of diabetes induces sustained hyperglycemia, but also participates in the development of chronic diabetic complications $(31,32)$. A large amount of medical evidence indicates that glucotoxicity is associated with endothelial dysfunction, which is an important factor involved in the development of macrovascular and microvascular diabetic complications $(32,33)$. Notably, a number of diabetic incidents are associated with inflammatory reactions (34-36). The inflammatory response is the important mechanism of endothelial dysfunction that can be promoted by glucotoxicity. Upon exposure to high glucose conditions, HUVECs produce high levels of proinflammatory cytokines, including TNF- $\alpha$ and IL-1 $\beta(37,38)$. In the present study, the results indicated that high glucose conditions decreased the HUVEC survival rate, increased cell apoptosis and promoted the protein and mRNA expression levels of TNF- $\alpha$ and $1 \mathrm{~L}-1 \beta$. Previous studies have demonstrated that AS-IV inhibits inflammation and protects endothelial function (26,39-41). AS-IV has also been revealed to decrease the serum levels of TNF-a in diabetic rats (39) and can inhibit the expression of inflammatory factors in TNF- $\alpha$-induced HUVECs (40). Furthermore, AS-IV can improve the structure of the aortic endothelium wall, inhibit over-activation of monocyte chemoattractant protein- 1 and TNF- $\alpha$ in diabetic rats (26) and protect endothelial cells from high glucose-induced barrier impairment (41). In the present study, no direct cytotoxic effect of ASIV was identified in HUVECs. Additionally, the present findings suggested that ASIV enhanced the HUVEC viability under high glucose conditions but also exerted an inhibitory effect on high-glucose-induced HUVEC apoptosis and inflammation. Notably, SP600125, an inhibitor of JNK, inhibited high-glucose-induced TNF- $\alpha$ and IL-1 $\beta$ expression 
A

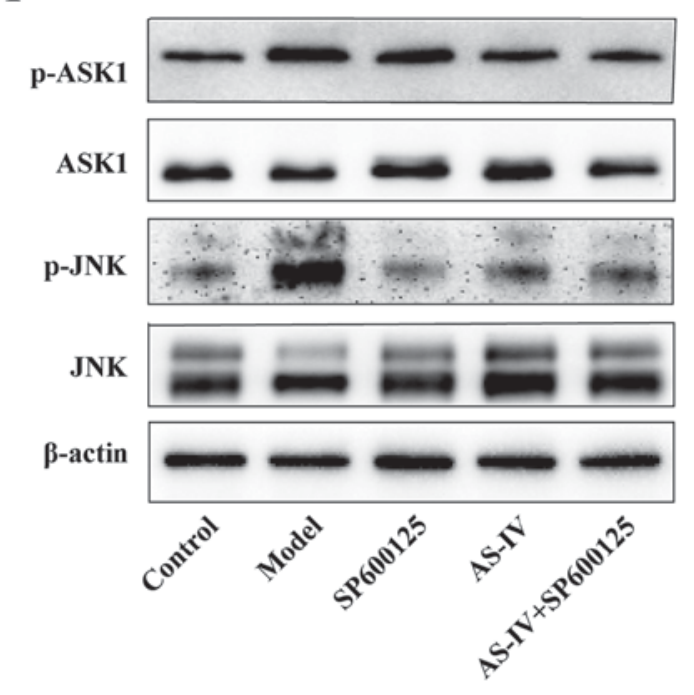

B

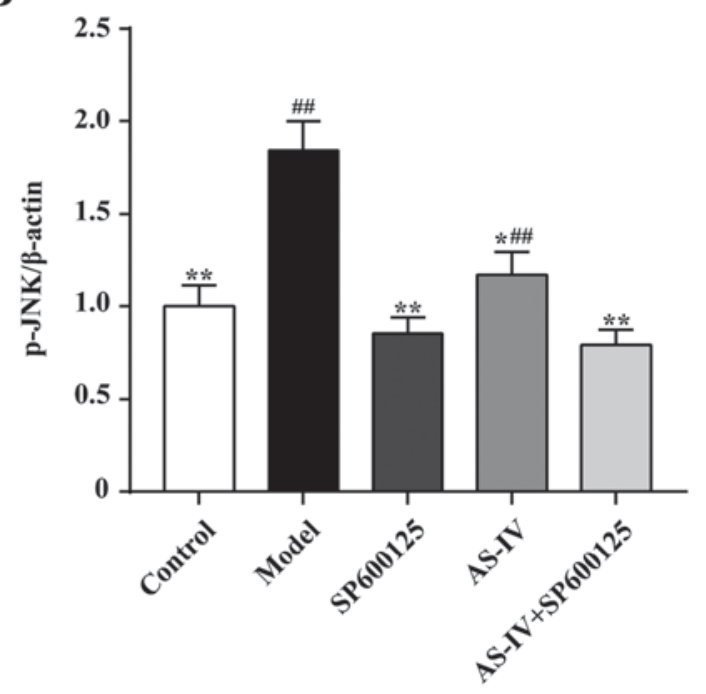

C

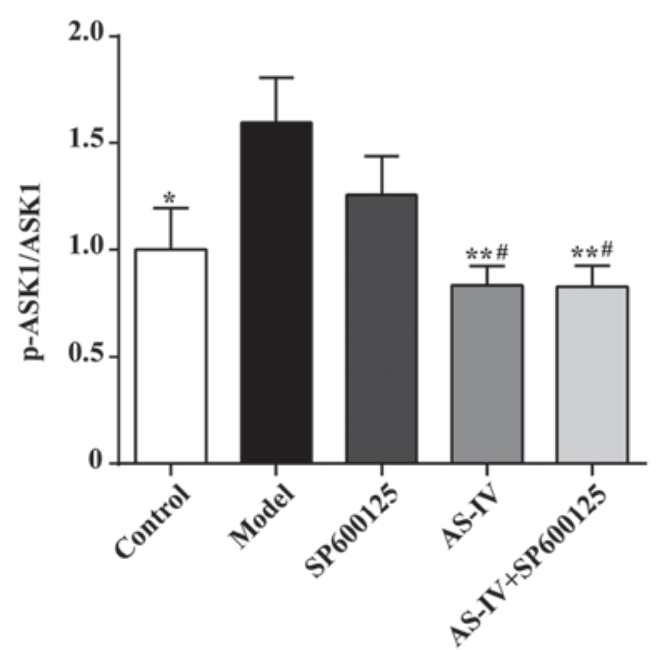

Figure 6. Effect of AS-IV on expression of JNK pathway components. (A) Western blot analysis of p-ASK1, ASK1, p-JNK and JNK protein. (B) JNK phosphorylation. (C) ASK1 phosphorylation. Data of three experiments were presented as the mean \pm standard deviation. ${ }^{*} \mathrm{P}<0.05$ and ${ }^{* *} \mathrm{P}<0.01 \mathrm{vs}$. the Model group; ${ }^{\#} \mathrm{P}<0.05$ and ${ }^{\# \#} \mathrm{P}<0.01$ vs. the SP600125 group. AS-IV, astragaloside IV; JNK, c-Jun $\mathrm{NH}_{2}$-terminal kinase; ASK1, apoptosis signal-regulating kinase-1; p-, phosphorylated-.

levels and cell apoptosis. Similar effects were also observed with AS-IV and SP600125 treatment. These results suggest that the effects of AS-IV are associated with the JNK signaling pathway.

The JNK signaling pathway is sensitive to the inflammatory response in diabetes complications. It has previously been suggested that, under the stimulation of inflammatory cytokines, which are involved in the endothelial dysfunction process, the JNK signaling pathway is activated and raises the number of endothelial cells damaged and cell apoptosis (18-20). Inflammatory cytokines are the primary activators of the JNK signaling pathway, which is a key regulator of pro-inflammatory gene expression (16). It has been reported that TNF- $\alpha$ induces increased phosphorylation of JNK in HUVECs (42). ASK1 is a member of the MAPK kinase kinase family, which activates JNK in response to a variety of stress stimuli (43). A previous study revealed that high glucose conditions induced the increase of ASK1 expression and its activity in HUVECs (44). In the present study, high glucose conditions in HUVECs resulted in increased ASK1 phosphorylation and JNK expression. However, a significant decrease in JNK and ASKI phosphorylation was indicated following treatment with AS-IV. In addition, an inhibitor of JNK, SP600125 (45), was used as a reference to compare the effectiveness of ASIV in the JNK signaling pathway. The results indicated that AS-IV could significantly inhibit the phosphorylation of high glucoseinduced JNK and ASK1, as well as the expression of TNF- $\alpha$ and IL-1 $\beta$. Furthermore, SP600125 significantly suppressed the phosphorylation of JNK but not ASK1. Compared with SP600125, the inhibitory effect of AS-IV on JNK phosphorylation was decreased compared with SP600125; however, there was no notable difference between SP600125 or AS-IV in combination with SP600125. Furthermore, SP600125 and the combination of AS-IV with SP600125 had the ability to inhibit ASK1 phosphorylation, whereas SP600125 did not. 
A

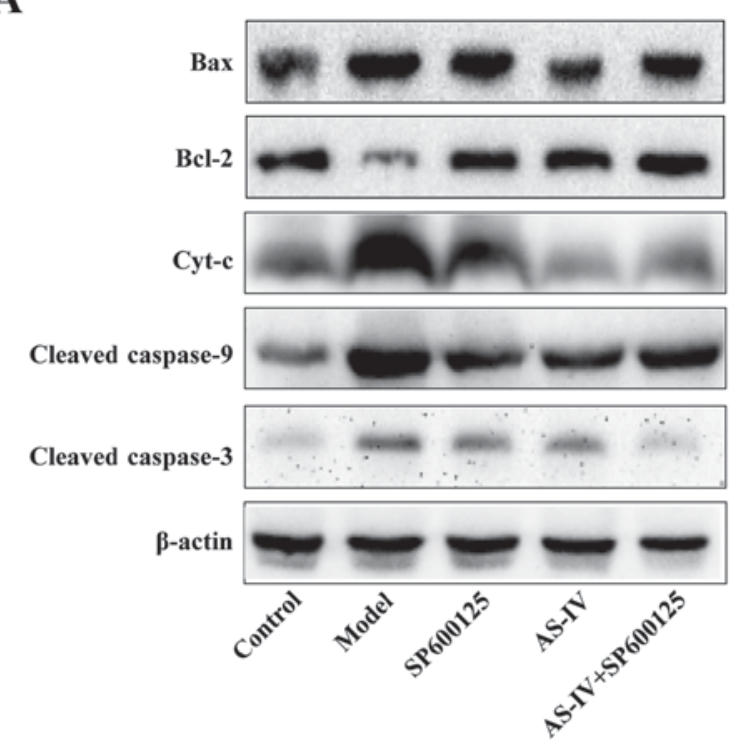

B

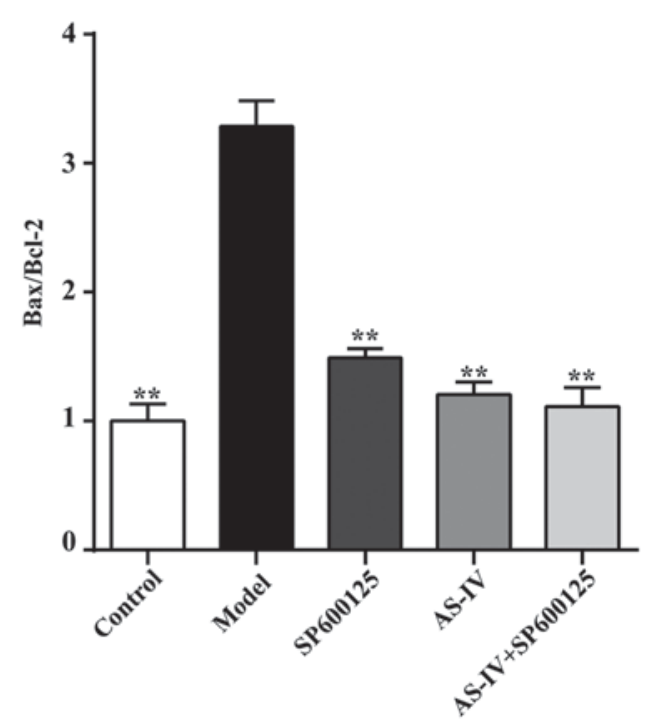

C

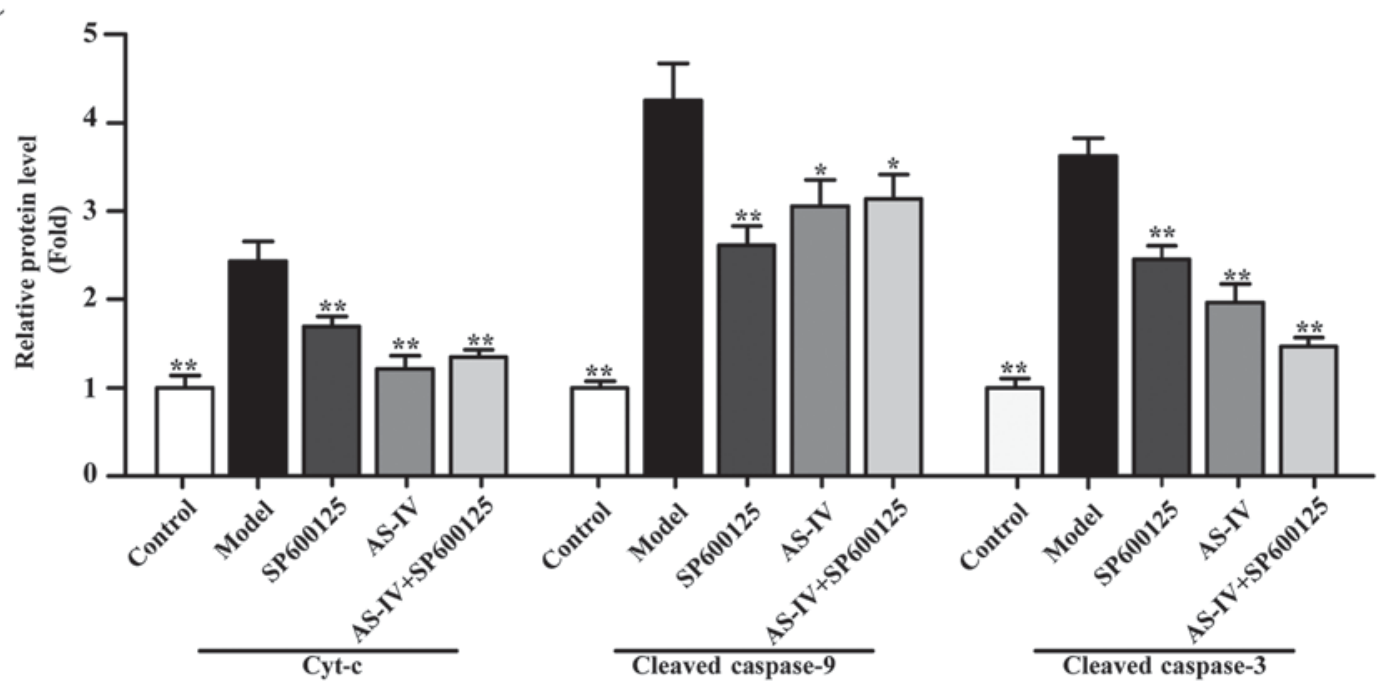

Figure 7. Mechanism of AS-IV on cell apoptosis of human umbilical vein endothelial cells stimulated with high glucose conditions. (A) Western blot analysis of Bax, Bcl-2 Cyt-c, cleaved-caspase-9 and cleaved-caspase-3. (B) Ratio of Bax/Bcl-2. (C) Expression levels of Cyt-c, cleaved-caspase-9 and cleaved-caspase-3. Data of three experiments were presented as the mean \pm standard deviation. ${ }^{*} \mathrm{P}<0.05$ and ${ }^{* *} \mathrm{P}<0.01$ vs. the Model group. AS-IV, astragaloside IV; Bax, B-cell lymphoma-2-associated X protein; Bcl-2, B-cell lymphoma-2.

The increase of endothelial cell apoptosis is one of the primary characteristics of endothelial dysfunction (4) and one of the most important effects on HUVECs in high glucose conditions (46). The present data indicated that high glucose conditions induced cell apoptosis. The JNK signaling pathway activates apoptotic signaling, either by promoting the expression of apoptotic genes in the nucleus or through modulating the activities of associated mitochondrial apoptotic proteins by phosphorylation events in the cytoplasm (23). In higher organisms, mitochondria-mediated apoptosis is the predominant pathway of cellular apoptosis (32). The pathways associated with mitochondrial JNK-mediated apoptosis include intrinsic apoptosis and extrinsic apoptosis pathways (23). In the intrinsic apoptosis pathway, JNK activates the internal cell mitochondrial apoptotic pathway and changes the mitochondrial structure and function, causing the release of Cyt-c into the cytoplasm (47). Following this, Cyt-c and an adaptor protein are combined with active caspase-9, forming the apoptotic bodies Cyt-c, caspase- 9 and apoptotic protease activating factor-1, which further activates caspase-3 and causes cell apoptosis (48). Furthermore, JNK can adjust the activity of Bcl-2 members by promoting the activation of apoptosis proteins Bax, which are dimers in the cytoplasm. This subsequently inhibits the protein expression of $\mathrm{Bcl}-2$ and regulates cell apoptosis $(48,49)$. In the present study, the expression levels of Bax, Cyt-c, cleaved-caspase- 9 and cleaved-caspase-3 were increased and Bcl-2 expression was decreased in high glucose-stimulated HUVECs. However, the expression levels of Bax, Cyt-c, cleaved-caspase- 9 and cleaved-caspase- 3 were reduced and $\mathrm{Bcl}-2$ expression was increased by treatment with ASIV. Compared with ASIV, the effects of SP600125 and the combination of AS-IV with SP600125 were not significantly different. This suggests that the ability of AS-IV and JNK inhibitors in regulating apoptotic proteins is similar. These data strongly support the mitochondria-mediated apoptosis pathway being involved in the pathogenesis of injury induced by high glucose conditions and ASIV could reduce cell apoptosis 
associated with the mitochondria-mediated apoptosis pathway. However, the effect of ASIV on mitochondrial morphology and mitochondrial membrane potential requires further observation in future studies to identify the mechanism of apoptosis inhibition.

In conclusion, the present study indicates that high glucosestimulation in HUVECs causes decreased cell activity, increased the expression of apoptosis and inflammatory factors and activated the JNK signaling pathway, and mitochondrial apoptosis pathway. The findings suggested that ASIV may be valuable for the prevention and treatment of diabetic vascular complications by reducing cell apoptosis and inflammatory reactions through the inhibition of the JNK signaling pathway and mitochondria-mediated apoptosis pathway. However, other relevant mechanisms underlying the effects of ASIV require further investigation.

\section{Acknowledgements}

The authors would like to thank the Key Laboratory of Xinan Medicine of Chinese Ministry of Education (Hefei, China) for their technical assistance.

\section{Funding}

The present study was supported by grants from the National Natural Science Foundation of China (grant nos. 81774286, 81573944 and 81273646), the Scientific Research Base of Traditional Chinese Medicine Clinical of State Administration of Traditional Chinese Medicine (grant no. JDZX2015001) and the National Basic Public Health Services Project of State Administration of Traditional Chinese Medicine (grant no. 20131012).

\section{Availability of data and materials}

The datasets used during the present study are available from the corresponding author on reasonable request.

\section{Authors' contributions}

ZF, GS and LY conceived the present study and edited the manuscript. LY, QW, YH, SY, LW, MH and YL performed the experiments and acquisition of data. ML and AJ were involved in analysis and interpretation of data. All authors discussed the results and implications and commented on the manuscript at all stages, as well as in the final approval of the version to be published.

\section{Ethics approval and consent to participate}

Not applicable.

\section{Patient consent for publication}

Not applicable.

\section{Competing interests}

The authors declare that they have no competing interests.

\section{References}

1. Huang D, Refaat M, Mohammedi K, Jayyousi A, Al Suwaidi J and Abi Khalil C: Macrovascular complications in patients with diabetes and prediabetes. Biomed Res Int 2017: 7839101, 2017.

2. Kaur R, Kaur M and Singh J: Endothelial dysfunction and platelet hyperactivity in type 2 diabetes mellitus: Molecular insights and therapeutic strategies. Cardiovasc Diabetol 17: 121, 2018.

3. Galley HF and Webster NR: Physiology of the endothelium. Br J Anaesth 93: 105-113, 2004.

4. Wang Q, Zhang M, Ding Y, Wang Q, Zhang W, Song P and Zou MH: Activation of NAD(P)H oxidase by tryptophan-derived 3-hydroxykynurenine accelerates endothelial apoptosis and dysfunction in vivo. Circ Res 114: 480-492, 2014.

5. Hotamisligil GS: Inflammation and metabolic disorders. Nature 444: 860-867, 2006

6. Donath MY: Targeting inflammation in the treatment of type 2 diabetes: Time to start. Nat Rev Drug Discov 13: 465-476, 2014.

7. Yan SF, Ramasamy R, Naka Y and Schmidt AM: Glycation, inflammation, and RAGE: A scaffold for the macrovascular complications of diabetes and beyond. Circ Res 93: 1159-1169, 2003.

8. Haidari M, Zhang W, Willerson JT and Dixon RA: Disruption of endothelial adherens junctions by high glucose is mediated by protein kinase $\mathrm{C}$-beta-dependent vascular endothelial cadherin tyrosine phosphorylation. Cardiovasc Diabetol 13: 105, 2014.

9. Sajja RK, Prasad S and Cucullo L: Impact of altered glycaemia on blood-brain barrier endothelium: An in vitro study using the hCMEC/D3 cell line. Fluids Barriers CNS 11: 8, 2014

10. Zhao XY, Wang XF, Li L, Zhang L, Shen DL, Li DH, Jin QS and Zhang JY: Effects of high glucose on human umbilical vein endothelial cell permeability and myosin light chain phosphorylation. Diabetol Metab Syndr 7: 98, 2015.

11. Chen G, Chen Y, Chen H, Li L, Yao J, Jiang Q, Lin X, Wen J and Lin L: The effect of NF-kappaB pathway on proliferation and apoptosis of human umbilical vein endothelial cells induced by intermittent high glucose. Mol Cell Biochem 347: 127-133, 2011.

12. Kageyama S, Yokoo H, Tomita K, Kageyama-Yahara N, Uchimido R, Matsuda N, Yamamoto S and Hattori Y: High glucose-induced apoptosis in human coronary artery endothelial cells involves up-regulation of death receptors. Cardiovas Diabetol 10: 73, 2011.

13. Ning RB, Zhu J, Chai DJ, Xu CS, Xie H, Lin XY, Zeng JZ and Lin JX: RXR agonists inhibit high glucose-induced upregulation of inflammation by suppressing activation of the NADPH oxidase-nuclear factor-kappaB pathway in human endothelial cells. Genet Mol Res 12: 6692-6707, 2013.

14. Owen GR, Achilonu I and Dirr HW: High yield purification of JNK1beta1 and activation by in vitro reconstitution of the MEKK1-->MKK4-->JNK MAPK phosphorylation cascade. Protein Expr Purif 87: 87-99, 2013.

15. Ip YT and Davis RJ: Signal transduction by the c-Jun N-terminal kinase (JNK)-from inflammation to development. Curr Opin Cell Biol 10: 205-219, 1998.

16. Newton K and Dixit VM: Signaling in innate immunity and inflammation. Cold Spring Harb Perspect Biol 4: pii: a006049, 2012.

17. Foletta VC, Segal DH and Cohen DR: Transcriptional regulation in the immune system: All roads lead to AP-1. J Leukoc Biol 63: 139-152, 1998.

18. Kralisch S, Sommer G, Stangl V, Köhler U, Kratzsch J, Stepan H, Faber R, Schubert A, Lössner U, Vietzke A, et al: Secretory products from human adipocytes impair endothelial function via nuclear factor kappaB. Atherosclerosis 196: 523-531, 2008.

19. Shen C, Li Q, Zhang YC, Ma G, Feng Y, Zhu Q, Dai Q, Chen Z, Yao Y, Chen L, et al: Advanced glycation endproducts increase EPC apoptosis and decrease nitric oxide release via MAPK pathways. Biomed Pharmacother 64: 35-43, 2010

20. Yamawaki H, Saito K, Okada M and Hara Y: Methylglyoxal mediates vascular inflammation via JNK and p38 in human endothelial cells. Am J Physiol Cell Physiol 295: C1510-C1517, 2008.

21. Breton-Romero R, Feng B, Holbrook M, Farb MG, Fetterman JL, Linder EA, Berk BD, Masaki N, Weisbrod RM, Inagaki E, et al: Endothelial dysfunction in human diabetes is mediated by Wnt5a-JNK signaling. Arterioscler Thromb Vasc Biol 36: 561-569, 2016.

22. Sabio G and Davis RJ: TNF and MAP kinase signalling pathways. Semin Immunol 26: 237-245, 2014.

23. Dhanasekaran DN and Reddy EP: JNK-signaling: A multiplexing hub in programmed cell death. Genes Cancer 8: 682-694, 2017. 
24. Li L, Hou X, Xu R, Liu C and Tu M: Research review on the pharmacological effects of astragaloside IV. Fundam Clin Pharmacol 31: 17-36, 2017.

25. You LZ, Lin YX, Fang ZH, Shen GM, Zhao JD and Wang TT: Research advances on astragaloside-IV in treatment of diabetes mellitus and its complications pharmacological effects Zhongguo Zhong Yao Za Zhi 42: 4700-4706, 2017 (In Chinese).

26. Yin Y, Qi F, Song Z, Zhang B and Teng J: Ferulic acid combined with astragaloside IV protects against vascular endothelial dysfunction in diabetic rats. Biosci Trends 8: 217-226, 2014.

27. Zhang WJ and Frei B: Astragaloside IV inhibits NF- $\kappa$ B activation and inflammatory gene expression in LPS-treated mice. Mediators Inflamm 2015: 274314, 2015.

28. Livak KJ and Schmittgen TD: Analysis of relative gene expression data using real-time quantitative PCR and the 2(-Delta Delta C(T)) method. Methods 25: 402-408, 2001.

29. Zhong W, Zou G, Gu J and Zhang J: L-arginine attenuates high glucose-accelerated senescence in human umbilical vein endothelial cells. Diabetes Res Clin Pract 89: 38-45, 2010.

30. Sheu ML, Chiang CK, Tsai KS, Ho FM, Weng TI, Wu HY and Liu SH: Inhibition of NADPH oxidase-related oxidative stress-triggered signaling by honokiol suppresses high glucose-induced human endothelial cell apoptosis. Free Radic Biol Med 44: 2043-2050, 2008.

31. Campos C: Chronic hyperglycemia and glucose toxicity: Pathology and clinical sequelae. Postgrad Med 124: 90-97, 2012

32. Ceriello A: Point: Postprandial glucose levels are a clinically important treatment target. Diabetes Care 33: 1905-1907, 2010.

33. Grassi D, Desideri G, Necozione S, Ruggieri F, Blumberg JB, Stornello M and Ferri C: Protective effects of flavanol-rich dark chocolate on endothelial function and wave reflection during acute hyperglycemia. Hypertension 60: 827-832, 2012.

34. Jourdan T, Godlewski G, Cinar R, Bertola A, Szanda G, Liu J, Tam J, Han T, Mukhopadhyay B, Skarulis MC, et al: Activation of the Nlrp3 inflammasome in infiltrating macrophages by endocannabinoids mediates beta cell loss in type 2 diabetes. Nat Med 19: 1132-1140, 2013

35. Masters SL, Dunne A, Subramanian SL, Hull RL, Tannahill GM, Sharp FA, Becker C, Franchi L, Yoshihara E, Chen Z, et al: Activation of the NLRP3 inflammasome by islet amyloid polypeptide provides a mechanism for enhanced IL-1 $\beta$ in type 2 diabetes. Nat Immunol 11: 897-904, 2010.

36. Wei X, Song H, Yin L, Rizzo MG, Sidhu R, Covey DF, Ory DS and Semenkovich CF: Fatty acid synthesis configures the plasma membrane for inflammation in diabetes. Nature 539: 294-298, 2016.

37. Wang W, Wang WH, Azadzoi KM, Dai P, Wang Q, Sun JB, Zhang WT, Shu Y, Yang JH and Yan Z: Alu RNA accumulation in hyperglycemia augments oxidative stress and impairs eNOS and SOD2 expression in endothelial cells. Mol Cell Endocrinol 426: 91-100, 2016.
38. Wang X, Wu Z, He Y, Zhang H, Tian L, Zheng C, Shang T, Zhu Q, Li D and He Y: Humanin prevents high glucose-induced monocyte adhesion to endothelial cells by targeting KLF2. Mol Immunol 101: 245-250, 2018

39. Zhang WJ, Hufnagl P, Binder BR and Wojta J: Antiinflammatory activity of astragaloside IV is mediated by inhibition of NF-kappaB activation and adhesion molecule expression. Thromb Haemost 90: 904-914, 2003.

40. Gui D, Huang J, Guo Y, Chen J, Chen Y, Xiao W, Liu X and Wang N: Astragaloside IV ameliorates renal injury in streptozotocin-induced diabetic rats through inhibiting NF- $\mathrm{KB}$-mediated inflammatory genes expression. Cytokine 61: 970-977, 2013.

41. Li HB, Ge YK, Zhang L and Zheng XX: Astragaloside IV improved barrier dysfunction induced by acute high glucose in human umbilical vein endothelial cells. Life Sci 79: 1186-1193, 2006.

42. Lo HM, Lai TH, Li CH and Wu WB: TNF- $\alpha$ induces CXCL1 chemokine expression and release in human vascular endothelial cells in vitro via two distinct signaling pathways. Acta Pharmacol Sin 35: 339-350, 2014.

43. Hattori K, Naguro I, Runchel C and Ichijo H: The roles of ASK family proteins in stress responses and diseases. Cell Commun Signal 7: 9, 2009

44. Yokoi T, Fukuo K, Yasuda O, Hotta M, Miyazaki J, Takemura Y, Kawamoto H, Ichijo H and Ogihara T: Apoptosis signal-regulating kinase 1 mediates cellular senescence induced by high glucose in endothelial cells. Diabetes 55: 1660-1665, 2006.

45. Shin M, Yan C and Boyd D: An inhibitor of c-jun aminoterminal kinase (SP600125) represses c-Jun activation, DNA-binding and PMA-inducible 92-kDa type IV collagenase expression. Biochim Biophys Acta 1589: 311-316, 2002.

46. Zhu W, Yuan Y, Liao G, Li L, Liu J, Chen Y, Zhang J, Cheng J and Lu Y: Mesenchymal stem cells ameliorate hyperglycemia-induced endothelial injury through modulation of mitophagy. Cell Death Dis 9: 837, 2018.

47. Tournier C: Requirement of JNK for stress-induced activation of the cytochrome c-mediated death pathway. Science 288: 870-874, 2000

48. Chauhan D, Li G, Hideshima T, Podar K, Mitsiades C, Mitsiades N, Munshi N, Kharbanda S and Anderson KC: JNK-dependent release of mitochondrial protein, Smac, during apoptosis in multiple myeloma (MM) cells. J Biol Chem 278: 17593-17596, 2003.

49. Kim BJ, Ryu SW and Song BJ: JNK- and p38 kinase-mediated phosphorylation of Bax leads to its activation and mitochondrial translocation and to apoptosis of human hepatoma HepG2 cells. J Biol Chem 281: 21256-21265, 2006.

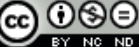

This work is licensed under a Creative Commons Attribution-NonCommercial-NoDerivatives 4.0 International (CC BY-NC-ND 4.0) License. 